\title{
Adverse reactions to intravenous iodinated contrast media: a prospective study
}

\author{
Dhruv J. Modi ${ }^{a, *}$, Darshan K. Mahyavanshi' ${ }^{a}$,Jay K. Kotechab, Ashutosh Dave ${ }^{\mathrm{c}}$, Harshad Shah
}

${ }^{\mathrm{a}}$ Resident, ${ }^{\mathrm{b}}$ Assistant Professor, ${ }^{\mathrm{c}}$ Professor, ${ }^{\mathrm{d}}$ Professor \& Head, Department of Radio Diagnosis, C.U. Shah Medical College \& Hospital, Surendranagar 363001, India

Received: 10 October 2012

Accepted: 30 October 2012

*Correspondence to:

Dr. Dhruv J. Modi,

Email: dr_dm85@yahoo.in

\begin{abstract}
Background: Adverse reactions to intravenous iodinated contrast media may be classified as general and organ-specific, such as contrast-induced nephrotoxicity. General adverse reactions may be sub classified into acute and delayed types. Acute general adverse reactions can range from transient minor reactions to life-threatening severe reactions. This study was done to determine clinical adverse effects of the iodinated contrast media.

Methods: Data of 899 consecutive patients at C.U. Shah Medical College and Hospital, Surendranagar, who received sodium meglumine diatrizoate intravenous iodinated contrast media during the period of May 2011 to April 2012, were collected for any adverse drug reactions.

Results: Out of 899, 189 patients developed adverse contrast reactions. The incidences of mild, moderate and severe adverse reactions were $19.47 \%$, $1.33 \%$ and $0.28 \%$, respectively. There were no differences in the incidence of adverse reactions according to gender (males 21.1\%; females $20.7 \%$; $p=$ $>0.05)$ or age $(p=>0.05)$. The incidence of adverse reactions was significantly higher in patients with a history of previous reactions $(50 \%)$ than in those with no history $(21.25 \% ; p=<0.05)$.

Conclusions: The skin was the most commonly affected site of reactions. In reactions, mild forms were more common compared to moderate and severe.
\end{abstract}

Keywords: Adverse Reactions, Intravenous Iodinated Contrast Media, Sodium Meglumine Diatrizoate

\section{INTRODUCTION}

Iodinated contrast media is the most commonly used drug in diagnostic radiology. However it can be used as in therapeutic purpose. Oral or rectal diatrizoate sodium is indicated for ${ }^{1}$ : 1. Radiographic examination of the gastrointestinal tract when the administration of barium sulfate is not recommended 2. Indicated in low concentration to delineate the stomach and intestinal loops in computed tomography (CT) of the body, 3. Used to treat meconium ileus in infants, 4 . In retrograde pyelography to evaluate abnormalities of the kidneys and ureter, 5. To determine the patency of the fallopian tubes.

Diatrizoate sodium is very poorly absorbed from the GI tract. ${ }^{1}$ Following intravesical instillation of diatrizoate sodium, only small amounts of the drug are absorbed into blood through the bladder. Some absorption of diatrizoate sodium into blood may also occur through serous membranes such as the peritoneum or pleura. The drug is rapidly absorbed after intramuscular or subcutaneous injection.

Diatrizoate sodium is rapidly distributed throughout extracellular fluid following intravascular administration. Less than $5 \%$ of the drug appears to be bound to plasma proteins.

Diatrizoate sodium is almost completely excreted in the urine, unchanged, via glomerular filtration in patients with normal renal function. When glomerular filtration is severely impaired, diatrizoate sodium appears to be secreted via the renal tubules. In patients with normal renal function, 95 to $100 \%$ of an intravascular dose of the drug is excreted in urine in 24 hours and 1 to $2 \%$ may be excreted in feces via biliary elimination and possibly via the intestinal mucosa. Trace amounts of the drug may also be excreted in sweat, tears, saliva, and gastric juice. 
Diatrizoates, when administered intravenously, cross the placenta and are evenly distributed in fetal tissues. When glomerular filtration is severely impaired, the medium appears to be secreted via the renal tubules. In patients with severely impaired renal function, the medium is slowly excreted in urine and 10 to $50 \%$ of an intravascular dose may be excreted in the feces, mainly via biliary elimination.

Although problems in humans have not been documented, since diatrizoates are distributed unchanged into breast milk, temporary discontinuation of breastfeeding is recommended for at least 24 hours following administration.

Adverse reactions to intravenous iodinated contrast media are broadly classified into general and organ-specific adverse effects, such as contrast induced nephrotoxicity, and cardiovascular, pulmonary, and neurotoxicity. Their incidence varies from 5 to $8 \%$ of patients who receive intravascular conventional, ionic agents. ${ }^{1}$ The general adverse reactions are further sub classified into acute and delayed reactions. ${ }^{2-4}$ Acute general adverse reactions are summarized in Table 1. Mild reactions are of short duration, self-limiting, and generally do not require specific treatment. However, moderate and severe reactions represent serious degrees of reactions that need immediate management. A delayed adverse reaction is defined as a reaction which occurs 1 hour to 1 week after contrast injection, which is predominantly a skin reaction. ${ }^{2}$

\section{METHODS}

The study was undertaken prospectively between May 1, 2011 and April 30, 2012. Those patients who received sodium meglumine diatrizoate intravenous iodinated contrast media at C.U. Shah Medical College and Hospital, Surendranagar, during above period were observed for development of any adverse drug reactions.

We used ionic, high osmolar contrast media, i.e., sodium meglumine diatrizoate, which was administered intravenously. Any indoor or outdoor patients requiring contrast enhanced CT or intravenous urography were eligible for this study. We excluded critically ill patients and those patients who underwent for coronary angiography.

Data for each patient were entered in a proforma which contained information on the patient's age, sex, indication for the investigation, previous medical history and previous history of adverse reactions.

Table: 1 classification on severity of reactions.

\begin{tabular}{|ccc|}
\hline Mild & Moderate & Severe \\
\hline Nausea & Severe vomiting & Pulmonary edema \\
\hline Vomiting & Extensive urticaria & Cardiac arrhythmias \\
\hline Limited urticaria & Laryngeal edema & Cardiac arrest \\
\hline Mild pallor & Dyspnea & Circulatory collapse \\
\hline Pain in injected extremity & Rigors & Unconsciousness \\
\hline
\end{tabular}

After a preliminary clinical examination, each study subject was followed up during the investigative procedure and for the next 2 hours for outdoor patients and 24 hours for indoor patients. The nature and severity of reactions were recorded.

The severity of reactions was classified as per Table 1 . All the data were collected by the single investigator. The distribution of adverse reactions according to contrast media used, age, sex and underlying disease of patients, presence of risk factors, and the system injected were determined. The chi-square test was used for statistical analysis.

\section{RESULTS}

Total 899 patients fulfilled the selection criteria and were included in the study. Out of them 189 had developed reactions. Table 2 gives the overall incidence of adverse reactions as well as the incidence of reactions classified according to severity.

Table 2: Distribution according to the incidence of adverse reactions to radio contrast media.

\begin{tabular}{|cccc|}
\hline \multirow{2}{*}{ Reaction } & \multicolumn{2}{c|}{ Total $(\boldsymbol{n = 1 8 9})$} & \multirow{2}{*}{ Incidence } \\
\cline { 2 - 3 } & No. & $\mathbf{\%}$ & \\
\hline Mild & 175 & 92.59 & 19.4 \\
\hline Moderate & 12 & 06.35 & 1.3 \\
\hline Severe & 2 & 01.06 & 0.2 \\
\hline Total & $\mathbf{1 8 9}$ & $\mathbf{1 0 0}$ & $\mathbf{2 1 . 0 2} *$ \\
\hline
\end{tabular}

*Out of total 899, 189 patients had developed reactions. 
Table 2 shows that $93 \%$ reactions developed in mild form followed by moderate and severe form which were $6 \%$ and $1 \%$ respectively.

Table 3: Association between gender wise distribution of patients with incidence of adverse reactions.

\begin{tabular}{|cccc|}
\hline \multirow{2}{*}{ Gender } & \multicolumn{2}{c}{ Adverse reaction } & \multirow{2}{*}{ Total } \\
\cline { 2 - 3 } & Presence & Absent & \\
\hline Male & 130 & 485 & 615 \\
\hline Female & 59 & 225 & 284 \\
\hline Total & $\mathbf{1 8 9}$ & $\mathbf{7 1 0}$ & $\mathbf{8 9 9}$ \\
\hline
\end{tabular}

Table 3 shows that statistically there was no significant difference between male and female with incidence of reaction $\left(x^{2}=001, d f=1, p=0.97\right)$. Both in male and female having incidence of reactions were almost same which was $21.1 \%$ and $20.7 \%$ respectively. In present study, numbers of male patients were more compared to female patients but the incidence of reactions was nearly similar.
In present study, majority of the patients were from the age group of 40-59 years and least in $>80$ years group which was 344 and 6 respectively. The incidence of reaction were found more in $<1$ year age group, followed by $20-39$ and $40-59$ years which was $28.57,21.88$ and 21.80 respectively (Table 4 ).

Table 5 shows that majority of patients came for contrast were having neurological disorders followed by renal and heapatobiliary i.e., 600, 206 and 33 respectively. Regarding incidence of reaction it was higher in patients came with respiratory diseases.

The association between previous reactions and occurrence of new reaction was statistically significant $(p=<0.05)$. So the patients came with previous history of reactions are having more chance to develop reactions again than without history of reactions.

Table 4: Association between the incidence of adverse reactions with age of the patients.

\begin{tabular}{|ccccc|}
\hline \multirow{2}{*}{ Age group } & \multicolumn{2}{c}{ Adverse reaction } & \multirow{2}{*}{ Total $(\boldsymbol{n}=\mathbf{8 9 9})$} & Incidence \\
\cline { 2 - 3 } & Presence & Absent & & \\
\hline$<1$ & 2 & 5 & 7 & 28.57 \\
\hline $1-19$ & 22 & 106 & 128 & 17.18 \\
\hline $20-39$ & 72 & 257 & 329 & 21.88 \\
\hline $40-59$ & 75 & 259 & 344 & 21.80 \\
\hline $60-79$ & 17 & 68 & 85 & 20.00 \\
\hline$>80$ & 1 & 5 & 6 & 16.67 \\
\hline Total & $\mathbf{1 8 9}$ & $\mathbf{7 1 0}$ & $\mathbf{8 9 9}$ & $\mathbf{1 0 0 . 0 0}$ \\
\hline
\end{tabular}

Table 5: Distribution of patients according to incidence of adverse reactions and underlying disease.

\begin{tabular}{|cccc|}
\hline Underlying disease & $\begin{array}{c}\text { No. with adverse } \\
\text { reactions }\end{array}$ & $\begin{array}{c}\text { Total no. of } \\
\text { patients }\end{array}$ & Incidence \\
\hline Cardiovascular & 3 & 11 & 27.27 \\
\hline Renal & 52 & 206 & 25.24 \\
\hline Neurological & 114 & 600 & 19.00 \\
\hline Gastrointestinal & 1 & 6 & 16.66 \\
\hline Heapatobiliary & 8 & 33 & 24.24 \\
\hline Respiratory & 5 & 18 & 27.77 \\
\hline Other & 6 & 25 & 24.00 \\
\hline
\end{tabular}


Table 6: Association between incidence of adverse reaction with history of previous reaction.

\begin{tabular}{|ccccc|}
\hline \multirow{2}{*}{$\begin{array}{c}\text { History of previous } \\
\text { reaction }\end{array}$} & Presence & Absent & Total & Incidence \\
\cline { 2 - 5 } & 5 & 5 & 10 & 50.00 \\
\hline Yes & 184 & 705 & 889 & 21.25 \\
\hline No & & & \\
\hline
\end{tabular}

Table 7: Incidence of adverse reactions according to the system affected.

\begin{tabular}{|lcc|}
\hline \multicolumn{1}{|c|}{ System affected } & No of patient affected & \% of patients affected \\
\hline Cutaneous (Total) & $\mathbf{1 2 5}$ & 66.13 \\
Itching & 38 & \\
Rash & 25 & \\
Warmth or flushing & 56 & \\
chills & 6 & 21.69 \\
& & \\
\hline Gastrointestinal (Total) & $\mathbf{4 1}$ & \\
Nausea/vomiting & 40 & 5.29 \\
Abdominal pain & 1 & \\
\hline Cardiovascular (Total) & & \\
Cardiac arrest & $\mathbf{1 0}$ & 4.23 \\
Hypotension & 7 & \\
\hline Central nervous system (Total) & 3 & 2.64 \\
Headache & $\mathbf{8}$ & \\
Giddiness & 5 & \\
\hline Respiratory & 3 & \\
Bronchospasm & $\mathbf{5}$ & \\
\hline
\end{tabular}

\section{DISCUSSION}

The results of this study may throw new light on racial influences concerning the development of adverse reactions following the administration of $\mathrm{CM}$. At present the relationship between race and $\mathrm{CM}$-induced reactions is not clear. Shahadi et al and Toniolo et $\mathrm{al}^{5}$ analysed more than 300000 case reports collected from several European countries, the United States, Canada and Australia and found the incidence to be strikingly similar in all countries. On the other hand, Ansell et $\mathrm{al}^{6}$, in a prospective 12 month survey in 272 hospitals in the United Kingdom, found a significantly increased (eightfold for severe reactions) risk for the development of CM-induced reactions in patients of Indian origin compared with native Britons. There was also a significantly increased risk in patients of Mediterranean origin, although to a lesser degree. The incidence of CMinduced mild reactions was in the present study high (Table 2) compared with that reported from studies conducted on the white population of the western world. ${ }^{5,6}$ The incidence of moderate and severe reactions was not higher. The relatively high incidence of mild reactions in our patients may be the result of genetic factors such as polymorphisms and mutations, which are known to influence the pharmacological properties of drugs and to show ethnic variations. ${ }^{7,8}$ It is of interest that in a study conducted by Jacobsson $\mathrm{BF}$ et $\mathrm{al}^{9}$ in which the incidence of reactions owing to the ionic agent metrizoate was high (31.2\% of patients), most of the subjects comprised the local ethnic race as well as subjects of Egyptian, Pakistani and Indian origin. Patients of Japanese origin also have a high incidence of CMinduced reactions. Higashi et $\mathrm{al}^{10}$ found an incidence of $16.6 \%$ of reactions due to ionic monomers and in another study $^{11}, 23.9 \%$ of patients who received the ionic agent ioxaglate developed adverse reactions.

Several studies ${ }^{12}$ have shown that there are no significant gender differences in the incidence of CM-induced reactions, as it was found in the present study.

It is well known that patients with an allergic diathesis are at an increased risk for developing adverse reactions ${ }^{13}$ and this is supported by our results (Tables 5 and 6).

It is well known that reactions to CM most commonly involve the skin ${ }^{14}$ and the present results corroborate this observation (Table 7). These reactions which present as 
warmth, chills, rashes and itching are described as anaphylactoid. $^{15}$

\section{CONCLUSION}

There was a high incidence of mild reactions in comparison to the incidence of moderate and severe reactions. Skin is the most commonly affected organ in contrast media induced reactions. There is no significant difference in age and sex in contrast media induced reactions. The incidence was slightly higher in patients with previous history of contrast media induced reactions.

\section{REFERENCES}

1. Diatrizoic acid - Compound Summary. Available at http://pubchem.ncbi.nlm.nih.gov/summary/sum mary.cgi?cid=2140. Accessed 19 June 2012.

2. Bush WH, Swanson DP. Acute reactions to intravascular contrast media: types, risk factors, recognition, and specific treatment. AJR Am J Roentgenol 1991;157:1153-61.

3. Webb JAW, Stacul F, Thomsen HS, Morcos SK. Late adverse reactions to intravascular iodinated contrast media. Eur Radiol 2003;13:181-4.

4. American College of Radiology Committee on Drugs and Contrast Media. ACR Manual on Contrast Media, 5th ed, American College of Radiology, Reston, VA 2004:5.

5. Shehadi WH, Toniolo G. Adverse reactions to contrast media: a report from the Committee on Safety of Contrast Media of the International Society of Radiology. Radiology 1980;137:299302.

6. Ansell G, Tweedie MC, West CR, Evans P, Couch L. The current status of reactions to intravenous contrast media. Invest Radiol 1980;15(6 Suppl):S32-9.

7. Benet LZ, Kroetz DL, Sheiner LB. Pharmacokinetics: the dynamics of drug absorption, distribution and elimination. In: Hardman JG, Limbird LE, et al, editors. The pharmacological basis of therapeutics. New York: McGraw Hill, 1996:3-27.

8. Kalow W. Pharmacogenetics in biological perspective. Pharmacol Rev 1997;49:369-79.

9. Jacobsson BF, Jorulf H, Kalantar MS, Narasimham DL. Nonionic versus ionic contrast media in intravenous urography: clinical trial in 1000 consecutive patients. Radiology 1988;167:601-5.

10. Higashi S, Takizawa K, Suzuki S, Nagashima J, Tamura S, Ishikawa M, et al. Prospective study of adverse reactions to contrast media administered intravenously: a comparison of low-osmolality and high-osmolality contrast media. Nippon Igaku Hoshasen Gakkai Zasshi 1988;48:1364-70.

11. Oi H, Yamazaki H, Matsushita M. Delayed vs. immediate adverse reactions to ionic and nonionic low osmolality contrast media. Radiat Med 1997;15:23-7.

12. Shehadi WH. Adverse reactions to intravascularly administered contrast media. A comprehensive study based on a prospective survey. Am J Roentgenol Radium Ther Nucl Med. 1975;124:145-52.

13. Palmer FJ. The RACR survey of intravenous contrast media reactions: Final report. Australas Radiol 1988;32:426-8.

14. Spring DB, Bettmann MA, Barkan HE. Nonfatal adverse reactions to iodinated contrast media: spontaneous reporting to the U.S. Food and Drug Administration, 1978-1994. Radiology 1997;204:325-32.

15. Cohan RH, Leder RA, Ellis JH. Treatment of adverse reactions to radiographic contrast media in adults. Radiol Clin North Am 1996;34:1055-76.

doi: 10.5455/2319-2003.ijbcp003712

Cite this article as: Modi DJ, Mahyavanshi DK, Kotecha JK, Dave A, Shah H. Adverse reactions to intravenous iodinated contrast media: a prospective study. Int J Basic Clin Pharmacol 2012;1:211-5. 